\title{
Study on the Low Voltage Ride-Through of Doubly-Fed Induction Generator Based on BP Neural Network
}

\author{
Gu Bo, Zhang Lingyun, Li Xiaodan and Qiu Daoyin \\ School of Electric Power, North China University of Water Resources and Electric \\ Power, Zhengzhou 450011, China \\ gb19820915@163.com
}

\begin{abstract}
In order to ensure that wind turbines could be online under the condition of power grid transient fault, the technology of low voltage ride-through (LVRT) for wind turbine has become a research focus of experts and scholars at home and abroad. In current wind turbine control strategy, the PI parameters of the control system keep unchanged when the wind turbine is in the process of LVRT, which affects the performance of the control system. Therefore, the adaptive PI parameter adjustment system based on BP neural network is proposed, which realize the adaptive adjustment of PI parameters in the process of LVRT. The simulation model of the LVRT process was built, the simulation results show that this control algorithm can effectively restrain the current oscillation caused by the voltage sag, shorten the fault recovery time of the system, and has a good dynamic performance. Besides, the adaptability and robustness of the system has been increased, which has improved the low voltage ride-through capability of the system.
\end{abstract}

Keywords: doubly-fed induction generator (DFIG); LVRT; PI Control; BP Neural Network

\section{Introduction}

As a clean renewable energy, wind power has attracted more and more attention in worldwide. In recent years, thanks to the support of national policy and the abundant wind resources, the development of wind power industry make a spurt of progress, the installed capacity of wind power is rising. But with the ever-increasing proportion of wind power in the power grid, the Influence of grid connected wind turbines for power system stability is more significant. Therefore, the effective of the LVRT control schemes must be taken, to ensure the stability of the grid connected operation of wind turbines [1-2].

The low voltage ride-through (LVRT) of wind farms refers to the condition of voltage dip fault, then the wind turbines are able to keep grid-connected and uninterrupted operation in a certain time, and even able to provide reactive power to the grid, support grid recovery. In various types of wind turbine, the doubly-fed induction generator (DFIG), with its wide speed range, the active and reactive power decoupling control, and the advantage of smaller capacity converter, etc. , quickly become one of the most widely used types of wind turbine at home and abroad. At present, to improve the LVRT capability of DFIG in case of grid voltage sag has become a research focus of experts and scholars at home and abroad [3-7].

The use of reactive power compensation scheme to realize the LVRT of wind turbine was proposed in [8], which meet the requirements of LVRT for the grid-connected wind power. The LVRT capability of DFIG has been improved effectively by adding hardware crowbar unloading circuit in case of power grid fault introduced in [9-10]. Adding unloading circuit in 
DC side of DFIG to absorb the excess energy, to achieve the purpose of voltage stability was put forward in [11]. Using series dynamic braking resistors (SDBR) to improve the LVRT capability of wind farms was proposed in [12].

In this presentation, the complete 5th order mathematical model of DFIG was established firstly, and then its current-mode control strategy is analyzed including torque control and voltage control. Secondly, the PI controller and the BP neural network were introduced briefly, and the adaptive PI parameter adjustment system based on BP neural network was proposed. Finally, the simulation model of the system is established, to simulate the PI parameters self-tuning in the process of LVRT, and analyze it. The simulation results show that, the algorithm of the adaptive PI parameter adjustment system based on BP neural network has realized the adaptive adjustment of PI parameters in the process of LVRT, effectively restrained the current oscillation caused by the voltage sag, and shortened the fault recovery time of system, which has improved the low voltage ride-through capability of the system.

\section{The Wind Turbine Model for DFIG}

\subsection{The Mathematical Model of DFIG}

The DFIG uses the wound-rotor induction generator, its stator winding is connected with power grid through the transformer, its rotor winding is fed through a back-to-back variablefrequency power converter, typically based on two AC/DC IGBT-based voltage source converters (VSCs), linked through a DC bus. The decoupling of the two VSCs (the rotor side converter and the grid side converter) through a capacitor allows separate control of the two converters. That is, the power converter decouples the network electrical frequency from the rotor mechanical frequency, enabling variable-speed operation of the wind turbine. A typical configuration of a DFIG wind turbine is shown schematically in Figure 1.

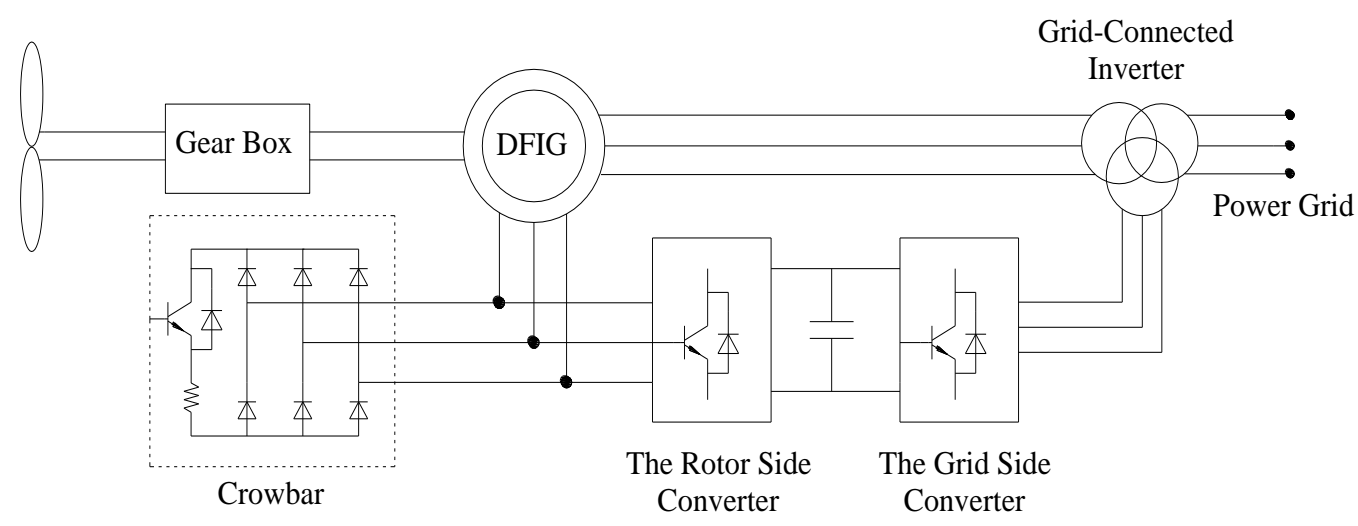

Figure 1. Typical Configuration of a DFIG Wind Turbine

In order to facilitate the analysis and control, the complex model of DFIG under ABC three-phase static coordinate system is usually converted to the simplified model of two-phase d-q synchronous rotating coordinate system. The DFIG model commonly has 8th order, 5th order, 4th order and 3rd order (ignoring the stator electrical transient) model [13-15]. This paper adopts 5th order mathematical model, the machine equations in pu form for the induction generator are given in equation (1) to (4), where all quantities except the synchronous speed are in pu. And swing equation for the mechanical system is given by equation (5). 


$$
\begin{aligned}
& \left\{\begin{array}{l}
\frac{d}{d t} \bar{i}_{d s}=\frac{\omega_{s}}{\bar{X}_{1}}\left[-\bar{R}_{s} \times \bar{i}_{d s}+\bar{X}_{1} \times \bar{i}_{q s}-\bar{e}_{d}+\bar{v}_{d s}-\frac{1}{\omega_{s}} \frac{d}{d t} \bar{e}_{q}\right] \\
\frac{d}{d t} \bar{i}_{q s}=\frac{\omega_{s}}{\bar{X}_{1}}\left[-\bar{R}_{s} \times \bar{i}_{q s}-\bar{X}_{1} \times \bar{i}_{d s}-\bar{e}_{q}+\bar{v}_{q s}+\frac{1}{\omega_{s}} \frac{d}{d t} \bar{e}_{d}\right]
\end{array}\right. \\
& \left\{\begin{array}{l}
\frac{d \bar{e}_{d}}{\partial \bar{t}}=-\frac{1}{\bar{T}_{0}}\left[\bar{e}_{d}+\frac{\bar{L}_{m}^{2}}{\bar{L}_{r r}} \times \bar{i}_{q s}\right]+s \times \omega_{s} \times \bar{e}_{q}-\omega_{s} \times \frac{\bar{L}_{m}}{\bar{L}_{r r}} \times \bar{v}_{q r} \\
\frac{d \bar{e}_{q}}{\partial \bar{t}}=-\frac{1}{\bar{T}_{0}}\left[\bar{e}_{q}-\frac{\bar{L}_{m}^{2}}{\bar{L}_{r r}} \times \bar{i}_{d s}\right]-s \times \omega_{s} \times \bar{e}_{d}+\omega_{s} \times \frac{\bar{L}_{m}}{\bar{L}_{r r}} \times \bar{v}_{d r}
\end{array}\right. \\
& \left\{\begin{array}{l}
\bar{i}_{d r}=\frac{1}{\bar{L}_{m}} \bar{e}_{q}-\frac{\bar{L}_{m}}{\bar{L}_{r r}} \bar{i}_{d s} \\
\bar{i}_{q r}=-\frac{1}{\bar{L}_{m}} \bar{e}_{d}-\frac{\bar{L}_{m}}{\bar{L}_{r r}} \bar{i}_{q s}
\end{array}\right. \\
& T_{e}=\bar{e}_{q} \times \bar{i}_{q s}+\bar{e}_{d} \times \bar{i}_{d s} \\
& \frac{d \omega_{r}}{d t}=\frac{1}{J} \times\left(T_{m}-T_{e}\right)
\end{aligned}
$$

Where, $\bar{v}_{d s}, \bar{v}_{q s}, \bar{v}_{d r}, \bar{v}_{q r}$, respectively are the d-q components of the stator and rotor voltage; $\bar{i}_{d s}, \bar{i}_{q s}, \bar{i}_{d r}, \bar{i}_{q r}$, respectively are the d-q components of the stator and rotor current; $\overline{\boldsymbol{e}}_{\boldsymbol{d}}$ and $\overline{\boldsymbol{e}}_{q}$ are the d-q components of the voltage behind a transient reactance; $\bar{R}_{s}$ is the stator resistance; $\bar{X}_{1}$ is the transient reactance of the induction generator; $\omega_{s}$ is synchronous speed; $\bar{L}_{r}$ and $\bar{L}_{m}$ are the equivalent self-inductance and mutual inductance of the rotor winding in the d-q coordinate; $\bar{L}_{r r}, \bar{T}_{0}$ is the per unit transient open-circuit time constant of the induction machine; $S$ is slip ratio; $T_{m}$ is the mechanical torque; $T_{e}$ is the electromagnetic torque and $J$ is the moment of inertia of generator.

\subsection{The Control Strategies of DFIG}

The dynamic control of the DFIG is provided through the back-to-back power converter, typically using the rotor-side converter to provide torque control together with terminal voltage or power factor $(\mathrm{PF})$ control, while the network-side converter is used to maintain the DC bus voltage.

The electrical control of the DFIG usually uses the current-mode control. In this control strategy, the rotor current is split into two orthogonal components, $\mathrm{d}$ and $\mathrm{q}$. The $\mathrm{q}$ component of the current is used to regulate the torque and the $\mathrm{d}$ component is used to regulate power factor or terminal voltage [13].

(1) Torque Control Scheme

The torque controller regulate the electromagnetic torque of the generator according to wind speed variations, to track the maximum power curve to make wind turbines run on the desiring reference point, so as to extract maximum power from the wind. Given a rotor speed 
measurement, the reference torque $T_{s p}$ can be provided by the wind turbine characteristic for maximum power extraction, which is manipulated to generate a reference value for the rotor current in the q axis $i_{\text {qref }}$. Neglecting the stator resistance and stator transients and using the stator flux oriented (SFO) reference frame, the d-axis component of the stator voltage is equal to zero $\bar{v}_{d s}=0$. According to the torque control scheme, the following equations can be got.

$$
\begin{aligned}
& \bar{i}_{q s}=\frac{\bar{L}_{m}}{\bar{L}_{s s}} \bar{i}_{q r} \\
& \bar{i}_{q r_{r e f}}=\frac{\bar{\omega}_{s} \bar{L}_{s s}}{\bar{L}_{m} \bar{v}_{q s}} \bar{T}_{s p}
\end{aligned}
$$

Where $\bar{L}_{s s}=\bar{L}_{m}+\bar{L}_{s}, \bar{T}_{s p}$ stands for the optimal torque set point provided from the torquespeed characteristic for maximum power extraction. A block diagram of this control scheme is shown in Figure 2.

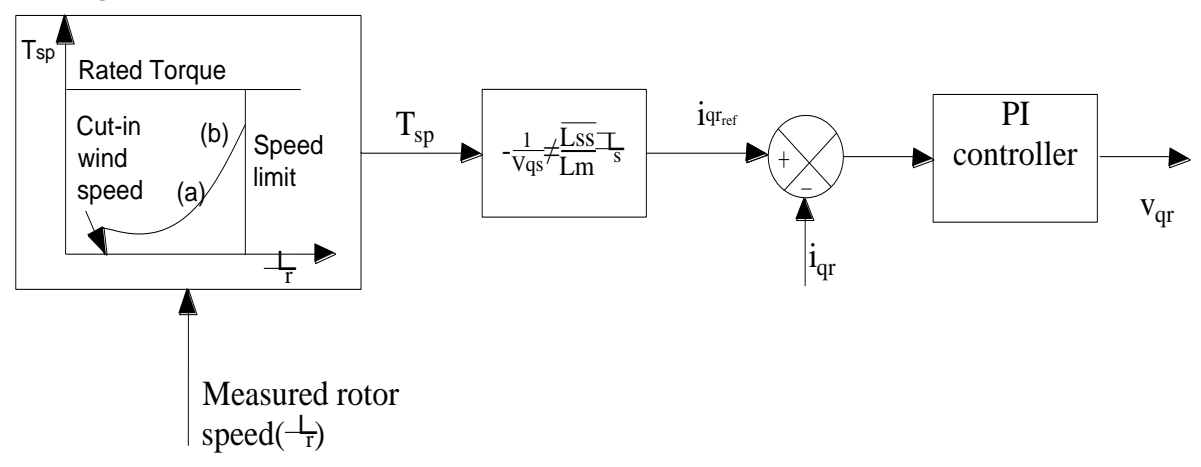

Figure 2. DFIG Torque Control Scheme

(2) Voltage Control Scheme

This control scheme is typically using the rotor-side converter to realize terminal voltage control or power factor control. Considering the reactive power of grid side, neglecting the stator resistance, and using the SFO reference frame, an expression is obtained for $\bar{Q}_{\text {grid }}$ :

$$
\bar{Q}_{\text {grid }}=-\frac{\bar{v}_{q s}^{2}}{\bar{\omega}_{s} \bar{L}_{s s}}+\frac{\bar{L}_{m} \bar{v}_{q s}}{\bar{L}_{s s}} \bar{i}_{d r}
$$

The rotor current component $\overline{i_{d r}}$ is divided into two components. One part is used to compensate for the generator excitation reactive power $\bar{i}_{d r-m}$, while the other $\bar{i}_{d r-g}$ is used to regulate the terminal voltage. A block diagram of the DFIG terminal voltage control scheme is shown in Figure 3. Where $K_{V C}$ is the control gain, it is used to improve terminal voltage or power factor control performance, $V_{\text {ref }}$ is the reference value of terminal voltage. 


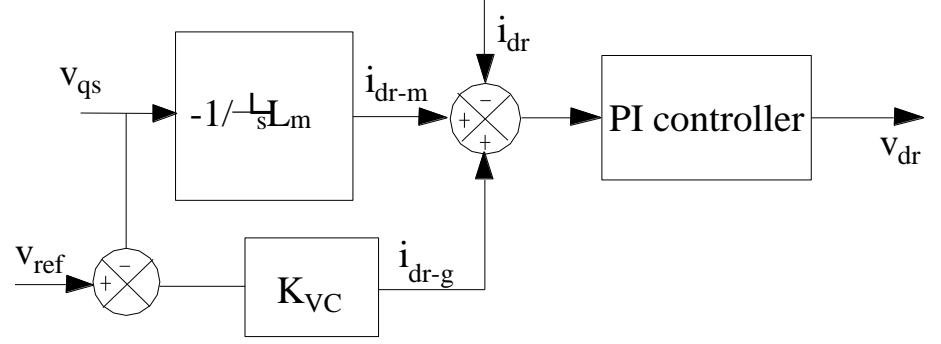

Figure 3. DFIG Terminal Voltage Control Scheme

\section{The PI Controller based on BP Neural Network}

\subsection{PI Controller}

PI control is one of the earliest developed control strategies using classical control theory, PI control is a simple algorithm, strong robustness and high reliability, and it is widely used in the process of production. The PI controller is composed of two parts, the proportion (P), which can quickly overcome the disturbances, and the integral (I) which eliminate the error on the basis of proportion. P and I are mutual coordination and restraint, to achieve closedloop control of the controlled device.

PI control is applicable to deterministic control system with accurate mathematical model. But with the continuous development of industry, the controlled device become more and more complex, it often face the problem of nonlinear, time-varying, and difficult to establish accurate mathematical model in the process of actual control. Therefore, the traditional PI controller cannot achieve the ideal control effect, exhibiting the defect in the ability of online adaptive adjustment [16].

\subsection{BP Neural Network}

BP (Back Propagation) neural network algorithm is also called error back propagation algorithm, it is a kind of intelligent control algorithm which has the ability of self-learning, adaptive and nonlinear processing. The main idea is that the error of output layer is propagated from back to front (reverse) layer-by-layer, to calculate the error of hidden layer indirectly. The algorithm is divided into two stages: The first stage (positive process), the output value of each unit is calculated by the input information transferring from the input layer through the hidden layer to the output layer; The second stage (back propagation process), each unit error of the hidden layer is calculated by the output error transferring from back to front, and using this error to correct the weights of previous layer. The BP network is a feed forward neural network, and the transfer function of the neurons is the S-type function, the output is a continuous quantity between $0-1$, it can achieve the arbitrarily nonlinear mapping from input to output [17-18]. With three-layer network as an example, the model structure is shown in Figure 4.

Where $\mathrm{m}$ is the number of the input nodes in the input layer and it takes different value according to the controlled device.

The input of network in the input layer is:

$$
O_{j}^{(1)}=x(j) \quad(j=1,2, \cdots, m)
$$

The input and output of network in the hidden layer is: 


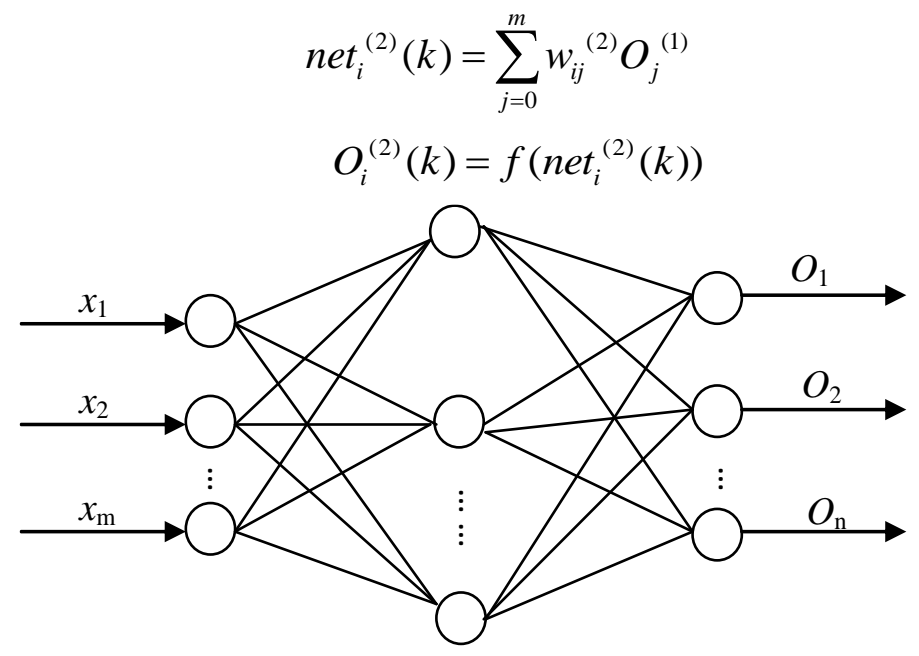

Figure 4. BP Neural Network Structure

Where $w_{i j}{ }^{(2)}$ is the weighting coefficient between the input layer and the hidden layer; The superscripts (1),(2),(3) respectively represent the input layer, hidden layer and output layer; Sigmoid function which is symmetrical positive and negative is taken for activation function of the hidden layer neurons:

$$
f(x)=\frac{e^{x}-e^{-x}}{e^{x}+e^{-x}}
$$

The input and output of network in the output layer is:

$$
\begin{gathered}
n e t_{i}^{(3)}(k)=\sum_{i=0}^{n} w_{i j}^{(3)} O_{j}^{(2)}(k) \\
O_{i}^{(3)}(k)=g\left(\operatorname{net}_{i}^{(3)}(k)\right)
\end{gathered}
$$

The non-negative sigmoid function is taken for activation function of the output layer neurons:

$$
g(x)=\frac{e^{x}}{e^{x}+e^{-x}}
$$

The performance indexes function is:

$$
E(k)=\frac{1}{2}(r(k)-y(k))^{2}
$$

Correction of the network weights along the direction of the fastest decline in performance function-negative gradient direction (gradient descent algorithm) is:

$$
\Delta w_{l i}^{(3)}(k)=-\eta \frac{\partial E(k)}{\partial w_{l i}^{(3)}}+\alpha \Delta w_{l i}^{(3)}(k-1)
$$

Where the $\eta$ is the learning rate and the $\alpha$ is the inertial coefficient.

From which the learning algorithm of weights in the output layer of network is obtained:

$$
\Delta w_{l i}^{(3)}(k)=\alpha \Delta w_{l i}^{(3)}(k-1)+\eta \delta_{l}^{(3)} O_{i}^{(2)}(k)
$$




$$
\delta_{l}^{(3)}=e(k) \operatorname{sgn}\left(\frac{\partial y(k)}{\partial \Delta u(k)}\right) \frac{\partial \Delta u(k)}{\partial O_{l}^{(3)}(k)} g^{\prime}\left(n e t_{l}^{(3)}(k)\right)
$$

Similarly the learning algorithm of the weights in the hidden layer is:

$$
\begin{gathered}
\Delta w_{i j}^{(2)}(k)=\alpha \Delta w_{i j}^{(2)}(k-1)+\eta \delta_{i}^{(2)} O_{j}^{(1)}(k) \\
\delta_{i}^{(2)}=f^{\prime}\left(n e t_{i}^{(2)}(k)\right) \sum_{l=1}^{3} \delta_{l}^{3} w_{l i}^{3}(k)
\end{gathered}
$$

Where $g(\times)^{\prime}=g(x)(1-g(x)), f(\times)^{\prime}=\frac{1}{2}\left(1-f^{2}(x)\right)$.

\subsection{Design of PI Controller based on BP Neural Network}

Since DFIG is a complex controlled device with high nonlinear and time-varying, the online dynamic adjustment of parameters cannot be achieved by traditional PI controller, which is difficult to meet the requirement of high control precision. In this paper, a control algorithm is proposed to achieve the PI parameters online self-tuning, which makes the combination of the BP neural network and PI controller. The schematic diagram of PI controller based on BP neural network is shown in Figure 5.

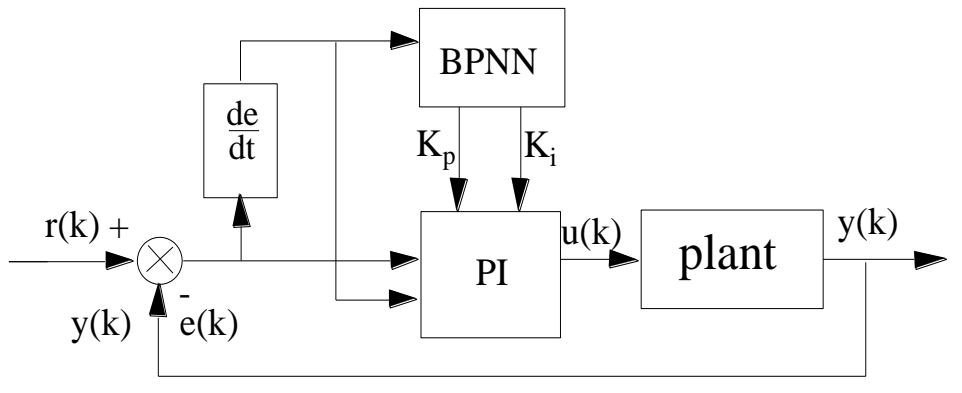

\section{Figure 5. PI Controller based on BP Neural Network}

Firstly, according to the square error of the given input $r(k)$ and system output $y(k)$ to adjust the weights of BP neural network (BPNN), so as to achieve the PI parameters selftuning. Secondly, the device is controlled by the PI controller to reduce the deviation $e(k)$ between the input and output of system.

In this control scheme, the output of BP neural network is corresponding to the optimized PI parameters.

That is $O_{1}^{(3)}(k)=k_{p}, O_{2}^{(3)}(k)=k_{i}$.

From which, the algorithm of PI controller based on BP neural network is as follows:

(1) Determining the structure of the BP neural network, including the number of nodes in the input layer, hidden layer and output layer. The initial value of the weighting coefficients in each layer is given, and the learning rate $\eta$ and inertia coefficient $\alpha$ is selected, make $k=1$;

(2) $r(k)$ and $y(k)$ are obtained by sampling, calculating the error of the moment $e(k)=r(k)-y(k)$; 
(3) Calculating the input and output of each layer neurons of the neural network, the output of output layer are $K_{p}$, and $K_{i}$;

(4) $u(k)$ is obtained by calculating the output of the PI controller;

(5) With neural network learning and online adjustment of the weighting coefficients, the adaptive adjustment of PI parameters is achieved;

(6) Setting $k=k+1$, return to step (1).

Establish BP neural network controller according to the summarized above, as shown in Figure 6.

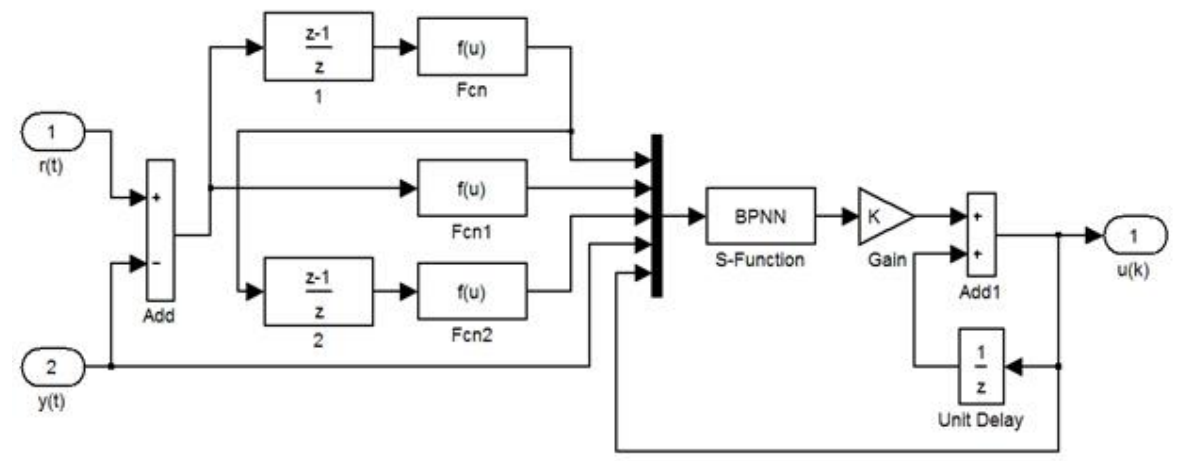

Figure 6. The Block Diagram of BP Neural Network Controller

In the diagram, the input signal is normalized, and BP algorithm is achieved by $\mathrm{S}$ Function.

\section{Experiments}

In order to verify the validity of the control scheme proposed for LVRT of DFIG, the simulation analysis has been carried on. With 2MW DFIG wind power system as the research object, the simulation model is established. And the 5th order model of wound rotor asynchronous motor is chosen for DFIG, the simulation parameters are as follows: rated power $2 \mathrm{MW}$, rated voltage $690 \mathrm{~V}$, rated frequency $50 \mathrm{HZ}$, stator resistance $0.00488 \mathrm{pu}$, stator leakage reactance $0.09241 \mathrm{pu}$, rotor resistance $0.00549 \mathrm{pu}$, rotor leakage reactance $0.09955 \mathrm{pu}$, airgap magnetizing reactance $3.95279 \mathrm{pu}$, lumped inertia constant $3.5 \mathrm{~s}$, wind speed is constant at $11 \mathrm{~m} / \mathrm{s}$, fault occurrence time is $20 \mathrm{~s}$, and the terminal voltage drops $20 \%$ and $40 \%$ respectively. The fault duration time is $0.2 \mathrm{~s} ; \mathrm{BP}$ neural network learning rate $\eta=0.2$, inertial coefficient $\alpha=0.4$, the random number in $[-0.5,0.5]$ are chosen as the initial value of weighting coefficient.

In this paper, the traditional PI control and optimization algorithm based on BP neural network are respectively used for the rotor current control during the fault. Changes of the rotor d-axis current for $20 \%$ and $40 \%$ voltage drop are shown in Figure 7 and Figure 8. Where the solid line indicates the LVRT process of the rotor $d$-axis current controlled by the traditional PI controller, and the dotted line indicates that controlled by the optimization algorithm based on BP neural network. Known from the figure, when the grid voltage sag, DFIG rotor d-axis current undergone significant oscillations, and the more severe voltage drops, the more intense the current oscillations (voltage drops $20 \%$, transient current peak is about $-0.15 \mathrm{pu}$; voltage drops $40 \%$, the transient current spikes over $-0.3 \mathrm{pu}$ ). Compared with the traditional PI control, the rotor current oscillation have been obviously weakened by using the BP optimization algorithm, the oscillation peak dropped about $0.05 \mathrm{pu}$, which reduce the 
impulse current of the rotor side converter and realize the protection to the rotor side converter and the LVRT control of DFIG.

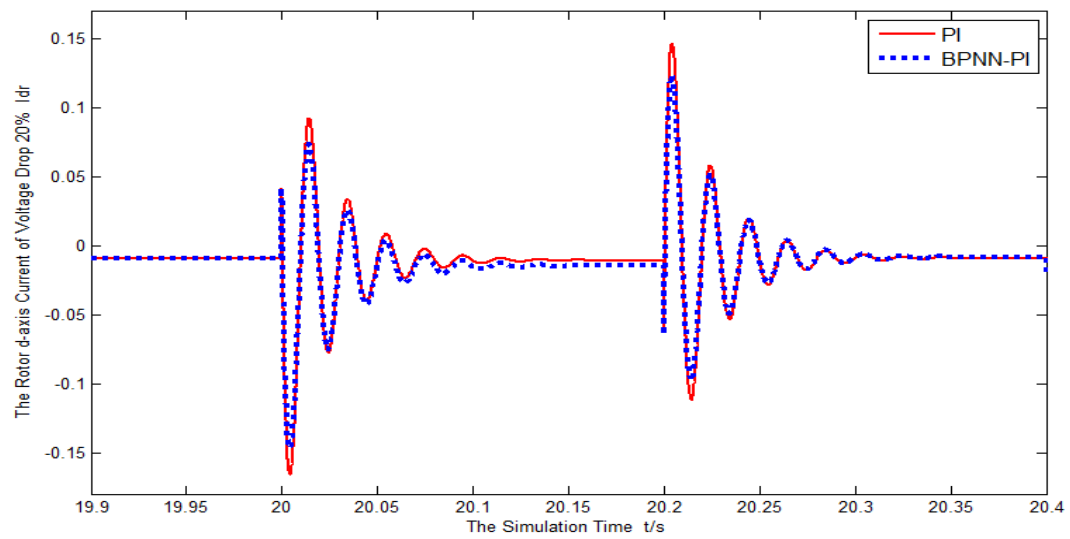

Figure 7. Rotor $d$-axis Current of Voltage Drop 20\%

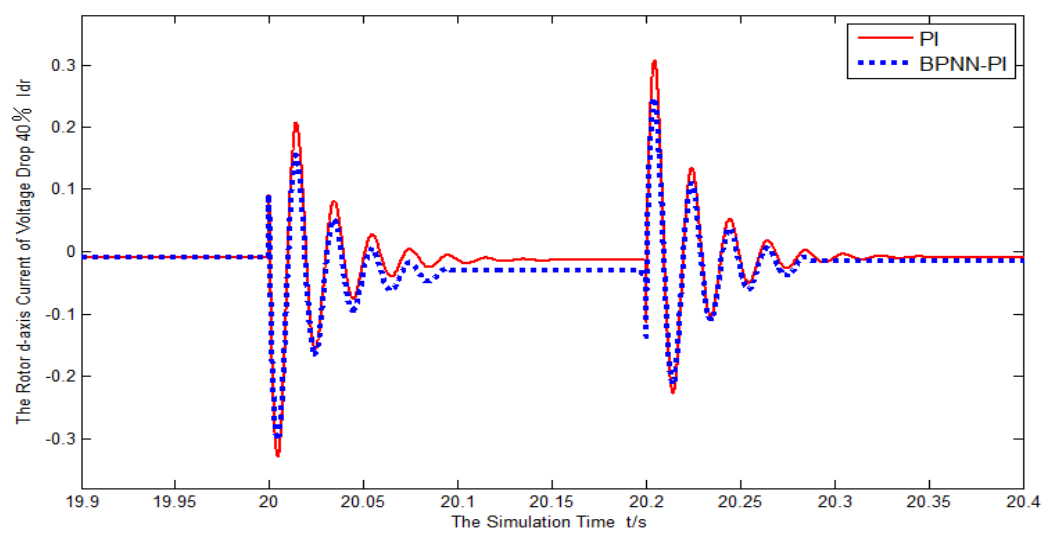

Figure 8. Rotor $d$-axis Current of Voltage Drop $40 \%$

The changes of the rotor q-axis current for $20 \%$ and $40 \%$ voltage drop are shown in Figure 9 and Figure 10. Where the solid line indicates the change of the rotor $q$-axis current controlled by the traditional PI controller, and the dotted line indicates that controlled by the BP optimization algorithm. Similarly, when the grid voltage sag, DFIG rotor $q$-axis current undergone significant oscillations, and the more severe voltage drops, the more intense the current oscillations (Transient current peak of voltage drops $40 \%$ is larger than $20 \%$ voltage sag current peak over 1pu about). And, compared with the PI controller, the rotor q-axis transient current peak value for BP algorithm is dropped about $0.5 \mathrm{pu}$, and the oscillation convergence is faster, the time which system reach to steady state is sped up.

Besides, when voltage drops the electromagnetic torque of the generator decreases rapidly while the mechanical torque is constant, this leads to the rotor speed of generator increase rapidly, and has an impact on the mechanical stress of the shaft system of wind turbines. So the weakened rotor current oscillation mentioned above, are beneficial to prolong the life of the mechanical system, and ensure the smooth operation of the system. 


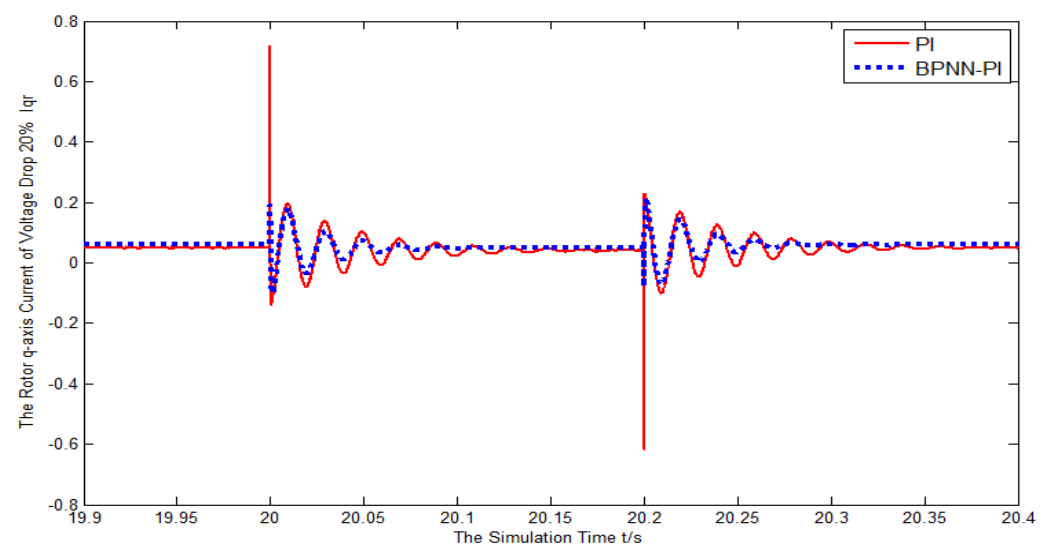

Figure 9. Rotor q-axis Current of Voltage Drop 20\%

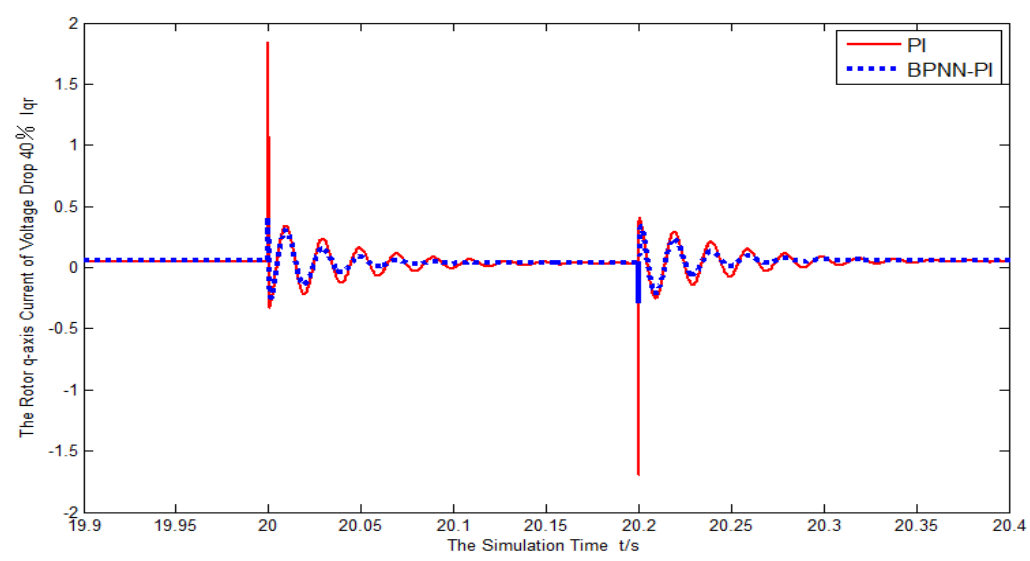

Figure 10. Rotor q-axis Current of Voltage Drop 40\%

\section{Conclusion}

In this paper, the complete 5th order mathematical model of the DFIG is established firstly, and its current-mode control strategy is analyzed. Secondly, on the basis of introducing the PI controller and the BP neural network briefly, the algorithm of the adaptive PI parameter adjustment system based on BP neural network is proposed. Finally, the simulation model of system is established. Making a simulation analysis of the control algorithm mentioned above, the simulation results show that, the algorithm of the adaptive PI parameter adjustment system based on BP neural network can weaken the rotor current oscillation effectively, which has protected the rotor side converter and reduced the impact of the mechanical stress of the wind turbines' shaft system. Besides, the convergence rate of current oscillation has been sped up obviously, so that the fault recovery time of system is shortened. Therefore, by using the algorithm of the adaptive PI parameter adjustment system based on BP neural network, the PI parameters self-tuning is realized which obtains a higher control precision and improves the LVRT capability of the system.

\section{References}

[1] Q. Niushan, Wind Energy Technology, Science Press, (2009). 
[2] T. Burton, N. Jenkins, D. Sharpe, and E. Bossanyi, Wind Energy Handbook, Wiley, (2001).

[3] A. D. Hansen and L. H. Hansen, "Wind Turbine Concept Market Penetration over 10 Years (1995-2004)", Wind Energy, vol. 10, no. 1, (2007), pp. 81-97.

[4] C. Jauch, J. Matevosyan, T. Ackermann, and S. Bolik, "International Comparison of Requirements for Connection of Wind Turbines to Power Systems", Wind Energy, vol. 8, no. 3, (2005), pp. 295-306.

[5] M. S. Vicatos and J. A. Tegopoulos, "Transient State Analysis of a Doubly-fed Induction Generator under Three Phase Short Circuit", IEEE Transactions on Energy Conversion, vol. 6, no. 1, (1991), pp. 62-68.

[6] J. Morren and S. W. H de Haan, "Short-circuit Current of Wind Turbines with Doubly Fed Induction Generator", IEEE Transactions on Energy Conversion, vol. 22, no. 1, (2007), pp. 174-180.

[7] A. Dittrich and A. Stoven, "Comparison of Fault Ride-through Strategies for Wind Turbines with DFIM Generators", 11th European Conference on Power Electronics and Applications, (2005), pp. 1-8.

[8] C. Chompoo-inwai, C. Yingvivatanapong, K. Methaprayoon and W. J. Lee, "Reactive Compensation Techniques to Improve the Ride-through Capability of Wind Turbine During Disturbance", IEEE Transactions on Industry Applications, vol. 41, no. 3, (2005), pp. 666-672.

[9] X. G. Zhang and D. G. Xu, "Research on Control of DFIG with Active Crowbar under Symmetry Fault Condition”, Electric Machines and Control, vol. 13, no. 1, (2009), pp. 99-103.

[10] R. Datta and V. T. Ranganathan, "Variable-speed Wind Power Generation Using Double Fed Wound Rotor Induction Machine", a comparison with alternative schemes, IEEE Transactions on Energy Conversion, vol. 17, no. 3, (2002), pp. 414-421.

[11] C. M. Abbey and G. Joós, "Effect of Low Voltage Ride Through (LVRT) Characteristic on Voltage Stability", IEEE Power Engineering Society General Meeting, (2005), pp. 1901-1907.

[12] H. F. Wang, G. Q. Lin, J. J. Qiu, and J. Cao, "Improvement of Low Voltage Ride-through Capability of Wind Farms by Use of Series Dynamic Braking Resistors", Automation of Electric Power Systems, vol. 32, no. 18, (2008), pp. 81-85.

[13] O. Anaya-Lara, N. Jenkins, J. Ekanayake, P. Cartwright and M. Hughes, "Wind Energy Generation: Modeling and Control", Wiley, (2009).

[14] I. Munteanu, A. I. Bratcu, N. A. Cutululis and E. Ceang, "Optimal Control of Wind Energy System", Springer-Verlag, (2008).

[15] J. B. Hu, D. Sun, Y. K. He and R. D. Zhao, "Modeling and Control of DFIG Wind Energy Generation System under Grid Voltage Dip", Automation of Electric Power Systems, vol. 30, no. 8, (2006), pp. 21-26.

[16] K. J. Åström and T. Hägglund, "PID controllers: Theory, Design and Tuning", Instrument Society of America, (1995).

[17] Z. Q. Bian and X. G. Zhang, "Pattern Recognition", Tsinghua University press, (1999).

[18] D. F. Zhang, "MATLAB Neural Network Applications and Design”, Machinery Industry Press, (2009).

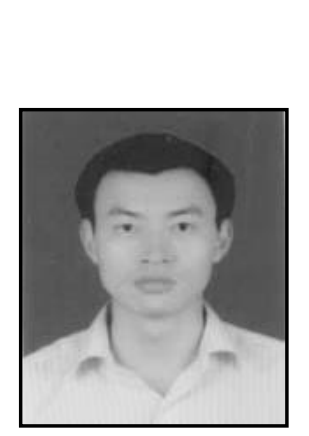

\section{Author}

Gu Bo, he received the Master degree in North China University of Water Resources and Electric Power in 2006. Currently, he is a lecturer at North China University of Water Resources and Electric power. His interests are in new energy generation technologies. 
International Journal of Hybrid Information Technology Vol.8, No.2 (2015) 